\title{
The lag effect with aurally presented passages
}

\author{
ROBERT N. KRAFT and JAMES J. JENKINS \\ University of Minnesota, Minneapolis, Minnesota 55455
}

\begin{abstract}
Two experiments examined free recall of aurally presented passages as a function of the size of the lag between repetitions of the passages. Experiment 1 demonstrated a significant lag effect up to lags of four passages. Experiment 2 extended the findings of the first experiment to lags of eight passages. Recall of the passages was shown to be a linear function of lag up to lags of eight passages.
\end{abstract}

It is well established in the folklore of storytelling, playwrighting, and teaching that repetition is the mother of retention. Many great orators, playwrights, and teachers have applied repetition so as to facilitate memory (Vale, 1976). It has also been repeatedly demonstrated in the psychology laboratory that verbal material is better recalled when it is repeated (e.g., Madigan, 1969; Melton, 1970). However, the critical variable involved in the memorial superiority of repeated material may not simply be repetition per se, but rather, the spacing of these repetitions. Generally, the empirical evidence overwhelmingly demonstrates the existence of a spacing effect: Recall performance is better when repetitions are spaced rather than massed (for reviews, see Hintzman, 1974; Melton, 1970). A more quantitative version of the spacing effect is the lag effect, which states that the extent of facilitation produced by repeating an item in a list of items is directly related to the number of intervening items (D'Agostino \& DeRemer, 1972; DeRemer \& D'Agostino, 1974; Hintzman, 1974, Madigan, 1969; Melton, 1967, 1970).

Past research has documented spacing and lag effects with consonant trigrams (Bjork \& Allen, 1970), lowand high-meaningful CVCs (Melton, 1970), low- and high-frequency words (e.g., Madigan, 1969; Maskarinec \& Thompson, 1976; Melton, 1967, 1970; Shaughnessy, 1977; Underwood, Kapelak, \& Malmi, 1976), homographs (Gartman \& Johnson, 1972; Nelson, 1971), and even pictures (Hintzman \& Rogers, 1973; Hintzman, Summers, \& Block, 1975; McCabe, Warren, Madigan, \& Jenkins, Note 1). However, the general issue of concern in this paper is the spacing effect at linguistic levels above the level of the word list. A more specific issue

Preparation of this paper was supported in part by grants to the University of Minnesota, Center for Research in Human Learning, from the National Science Foundation (BNS-75-03016), the National Institute of Child Health and Human Development (HD-01136), and the Graduate School of the University of Minnesota. Special thanks are due to Decisions and Designs, Inc., for supporting the completion of this paper. Requests for reprints should be sent to Robert Kraft, Decisions and Designs, Inc., Suite 600, 8400 Westpark Drive, P.O. Box 907, McLean, Virginia 22101. concerns the shape of the lag function at these higher linguistic levels.

Generally, the spacing effect has held up at the level of connected discourse. Rothkopf and Coke (1963) examined the effect of massed vs. spaced repetitions of sentences embedded within a short passage. Cued recall for noun phrases in the repeated sentences yielded a highly significant spacing effect. In a later study, Rothkopf and Coke (1966) demonstrated a spacing effect with sentences embedded in the same short passage, even when the phrasing of the sentences differed in the two presentations. Carter and Carrier (1976) compared recall of facts from massed vs. spaced sentences embedded in a passage of moderate length $(1,067$ words) and found a significant spacing effect. Further, Kraft, Kreps, and Jenkins (Note 2) demonstrated a significant spacing effect with recall of sentences embedded in relatively long essays (25,000 words).

Of particular interest in the first experiment reported here is the effect of spacing and lag with higher level linguistic materials that are presented aurally, as in a speech or a lecture. There are two reasons for this particular focus. First, there have been no conclusive demonstrations of the lag effect with connected discourse. DeRemer and D'Agostino (1974) did demonstrate a significant lag effect in free recall of object phrases; however, the presentation material consisted of unrelated sentences. Second, there is some evidence that the spacing and lag effects operate differently depending on whether the linguistic material is presented visually or aurally (Melton, 1970; Waugh, 1970). Waugh (1970) found that rate of presentation is a critical variable in the spacing effect when presentation is auditory, but not when presentation is visual. Melton (1970) did demonstrate significant lag effects with both visually and aurally presented words, but the slope of the lag function was far greater for the visually presented material, especially when the materials consisted of words from several different word classes. These findings are significant because all of the above studies that demonstrated a spacing effect with connected discourse used visual presentations, not aural (Carter \& Carrier, 1976; DeRemer \& D'Agostino, 1974; Rothkopf \& Coke, 1963, 1966; Kraft et al., Note 2). 


\section{EXPERIMENT 1}

\section{Method}

Subjects. Twenty eight students enrolled in the introductory psychology course at the University of Minnesota served as subjects in order to receive optional points for the course. There were approximately equal numbers of males and females.

Materials. Four sequences of 46 brief passages were recorded on a cassette tape recorder. Each passage was between 100 and 150 words and described a historical event, a biological phenomenon, or a famous person. Each sequence of passages consisted of four buffer paragraphs: two at the beginning and two at the end, including six once-presented, six Lag 0 , six Lag 2, and six Lag 4 passages. A Lag 0 passage was one that was repeated with no intervening passages. A Lag 2 passage had two intervening passages between presentations, and a Lag 4 passage had four intervening passages. The sequences each contained 28 different passages: 4 buffer passages and 24 target passages (6 once presented, $6 \mathrm{Lag} 0,6 \mathrm{Lag} 2$, and $6 \mathrm{Lag} 4$ ). The four different sequences were created by assigning each set of six target paragraphs to each one of the four lag conditions.

Procedure and Design. Each group of subjects heard one sequence of passages played to them on a tape recorder. Following presentation, subjects were given an immediate free recall task that required them to label each passage and then give a one-sentence summary of the passage. A passage was scored as being correctly recalled if the subject gave a title and followed it with an appropriate description. For example, for the passage about Buffalo Bill, the subject would be required to write "Buffalo Bill" and follow that with at least one piece of information from that passage. This experiment involved a withinsubjects design consisting of four different treatments (once presented, Lag 0, Lag 2, and Lag 4).

\section{Results and Discussion}

A summary of the results is illustrated in Figure 1. There was a significant effect of lag $[F(3,81)=23.86$, $\mathrm{p}<.001, \mathrm{MSe}=1.61]$. Further, pairwise comparisons between adjacent lag conditions were all significant. More Lag 4 passages were recalled than $\operatorname{Lag} 2[\mathrm{~F}(1,27)=$ $14.04, \mathrm{p}<.001, \mathrm{MSe}=1.71]$, and more Lag 2 passages

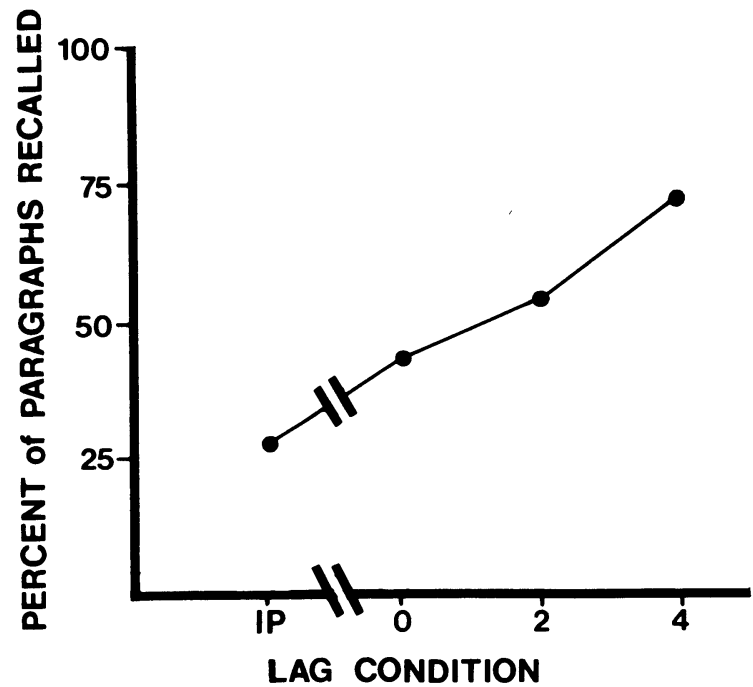

Figure 1. Percent of paragraphs recalled as a function of lag in Experiment 1. were recalled than $\operatorname{Lag} 0[\mathrm{~F}(1,27)=4.685, \mathrm{p}<.05$, $\mathrm{MSe}=2.38]$. In addition, an analysis of trend yielded a highly significant linear relationship between lag and recall $[\mathrm{F}(1,27)=85.62, \mathrm{p}<.001, \mathrm{MSe}=1.34]$.

These results demonstrate that the lag effect holds up with aurally presented passages with lags up to four. However, the only comparison that truly represents a lag effect is the comparison of Lag 2 and Lag 4 passages. The remaining comparisons (Lag 0/Lag 2 and Lag 0/ Lag 4) represent a spacing effect. Experiment 2 was conducted in order to extend the results from the first experiment and to map the lag function more precisely.

\section{EXPERIMENT 2}

\section{Method}

Subjects. Thirty-two students enrolled in the introductory psychology course at the University of Minnesota served as subjects in order to receive optional points for the course. There were approximately equal numbers of males and females.

Materials and Procedure. Four sequences of 44 brief passages were recorded on a cassette tape recorder. The passages were drawn from the set of passages used in Experiment 1. Each sequence of passages consisted of four buffer passages: two at the beginning and two at the end, including five Lag 2 , five Lag 4, five Lag 6, and five Lag 8 passages. The sequences each contained 24 different passages: 4 buffer passages and 20 target passages. The four sequences were created by assigning each set of five target paragraphs to each one of the four lag conditions. The procedure was identical to the procedure in Experiment 1.

\section{Results and Discussion}

A summary of the results is illustrated in Figure 2. There was a significant effect of lag $[F(3,93)=4.56$, $\mathrm{p}<.01, \mathrm{MSe}=1.23]$. Further, more Lag 4 passages were recalled than $\operatorname{Lag} 2[\mathrm{~F}(1,31)=5.32, \mathrm{p}<.05$, $\mathrm{MSe}=1.06]$, as in Experiment 1. However, compari-

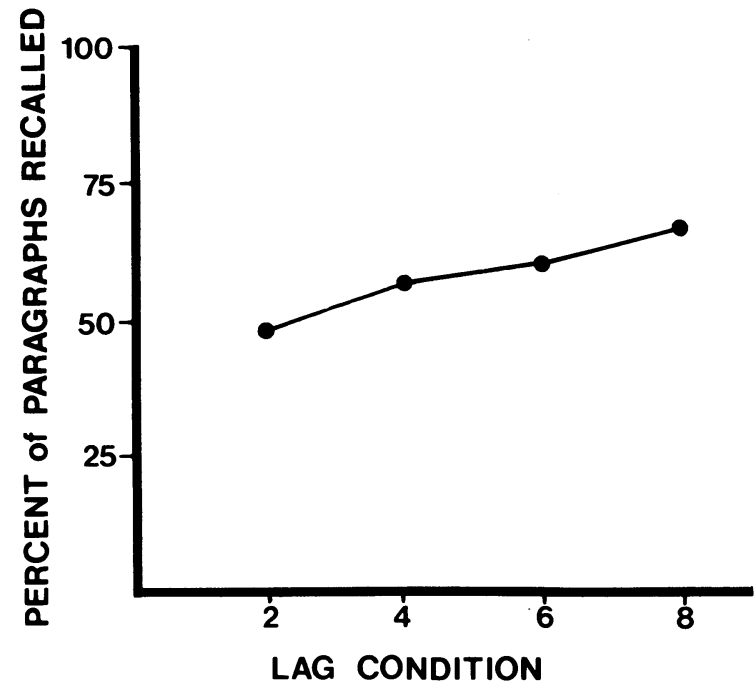

Figure 2. Percent of paragraphs recalled as a function of lag in Experiment 2. 
sons between Lag 4 and Lag 6 passages and between Lag 6 and Lag 8 passages were not significant. An analysis of trend did yield a highly significant linear effect $[\mathrm{F}(1,31)=18.17, \mathrm{p}<.001, \mathrm{MSe}=.877]$, thereby indicating that recall of the passages was a linear function of lag up to lags of eight passages.

In summary, the lag effect does persist with aurally presented passages. Further work needs to be done, however, to determine the shape of the lag function with lags greater than eight and, more importantly, to explore the nature of the spacing and lag effects with passages embedded within a coherent aural presentation, such as a speech or a lecture. Certainly, these experiments suggest that simply repeating material is not sufficient for optimizing retention and that the spacing of repetitions is a critical variable in determining how much the listener remembers.

\section{REFERENCE NOTES}

1. McCabe, L., Warren, R., Madigan, S. A., \& Jenkins, J. J. Within-list repetitions of types and tokens: The disappearing lag effect when pictures are used. Unpublished manuscript, 1976.

2. Kraft, R. N., Kreps, J., \& Jenkins, J. J. The lag effect in connected discourse. Paper presented at the meeting of the American Educational Research Association, Boston, April 1980.

\section{REFERENCES}

Bjork, R. A., \& Allen, T. W. The spacing effect: Consolidation or differential encoding? Journal of Verbal Learning and Verbal Behavior, 1970, 9, 567-572.

Carter, J. F., \& Carrier, C. Prose organization and recall. Contemporary Educational Psychology, 1976, 1, 329-345.

D'Agostino, P. R., \& DeRemer, P. Item repetition in free and cued recall. Journal of Verbal Learning and Verbal Behavior, 1972, 11, 54-58.

DeRemer, P., \& D'Agostino, P. R. Locus of distributed lag effect in free recall. Journal of Verbal Learning and Verbal Behavior, 1974, 13, 167-171.
Gartman, L. M., \& Johnson, N. F. Massed versus distributed repetition of homographs: A test of the differential encoding hypothesis. Journal of Verbal Learning and Verbal Behavior, 1972, 11, 801-808.

Hintzman, D. L. Theoretical implications of the spacing effect. In R. L. Solso (Ed.), Theories in cognitive psychology: The Loyola symposium. Potomac, Md: Erlbaum, 1974.

Hintzman, D. L., \& Rogers, M. K. Spacing effects in picture memory. Memory \& Cognition, 1973, 1, 430-434.

Hintzman, D. L., Summers, J. J., \& Block, R. A. What causes the spacing effect? Some effects of repetition, duration, and spacing on memory for pictures. Memory \& Cognition, 1975, 3, 287-294.

Madigan, S. W. Intraserial repetition and coding processes in free recall. Journal of Verbal Learning and Verbal Behavior, $1969,8,828-835$.

Maskarinec, A. S., \& Thompson, C. P. The within-list distributed practice effect: Tests of the varied context and varied encoding hypotheses. Memory \& Cognition, 1976, 4, 741-746.

Melton, A. W. Repetition and retrieval from memory. Science, 1967, 158, 532.

Melton, A. W. The situation with respect to the spacing of repetitions and memory. Journal of Verbal Learning and Verbal Behavior, 1970, 9, 596-606.

Nelson, L. Effects of subjective organization on single trial free recall of homographs under massed versus distributed practice. Dissertation Abstracts International, 1971, 33(3-B), 1310.

Rотнкорғ, E. Z., \& CoKe, E. U. Repetition interval and rehearsal method in learning equivalences from written sentences. Journal of Verbal Learning and Verbal Behavior, 1963, 2, 406-416.

Rотнкорғ, E. Z., \& CoKE, E. U. Variations in phrasing, repetition intervals, and the recall of sentence material. Journal of Verbal Learning and Verbal Behavior, 1966, 5, 86-91.

Shaughnessy, J. J. Long-term retention and the spacing effect in free-recall and frequency judgments. American Journal of Psychology, 1977, 90, 587-598.

Underwood, B. J., Kapelak, S. M., \& Malmi, R. A. The spacing effect: Additions to the theoretical and empirical puzzles. Memory \& Cognition, 1976, 4, 391-400.

VALE, E. The techniques of screenplay writing. New York: Crossett \& Dunlop, 1976.

WAUGH, N. C. On the effective duration of a repeated word. Journal of Verbal Learning and Verbal Behavior, 1970, 9, 587-595.

(Received for publication February 17, 1981.) 